Article

\title{
A National Study on Protecting Infrastructure and Public Buildings Against Sea Level Rise and Storm Surge
}

\author{
Paul Chinowsky ${ }^{1^{*}}$ and Jacob Helman ${ }^{2}$ \\ 1 University of Colorado Boulder, Program in Environmental Design; paul.chinowsky@colorado.edu \\ 2 Resilient Analytics, Inc., jhelman@resilient-analytics.com \\ * Correspondence: paul.chinowsky@colorado.edu;
}

\begin{abstract}
The national study analyzes sea level rise (SLR) impacts based on 36 different SLR and storm surge scenarios across 5.7 million geographic locations and 3 time periods. Taking an approach based on engineering design guidelines and current cost estimates, the study details projected cost impacts for states, counties, and cities. These impacts are presented from multiple perspectives including total cost, cost per-capita, and cost per-square mile. The purpose of the study is to identify specific locations where infrastructure is vulnerable to rising sea levels. The study finds that Sea Level Rise (SLR) and minimal storm surge is a $\$ 400$ billion threat to the United States by 2040 that includes a need for at least 50,000 miles of protective barriers. The research is limited in its scope to protecting coastal infrastructure with sea walls. Additional methods exist and may be appropriate in individual situations. The study is original in that it is a national effort to identify infrastructure that is vulnerable as well as the cost associated with protecting this infrastructure.
\end{abstract}

Keywords: sea level rise; climate change; infrastructure; coastal engineering

\section{Introduction}

Climate change presents a wide range of challenges for infrastructure owners, planners, and users. Of these potential impacts, the one that is predicted to have one of the largest ramifications in the United States is Sea Level Rise (SLR). If a rising temperature continues to manifest on a global scale, then sea level rise will occur due to a combination of thermal expansion of sea water and the melting of land-based ice into the ocean [1]. The consequences of this sea level rise on coastal road networks, buildings and infrastructure due to economic, social and environmental costs are predicted to be substantial [2-4].

According to NOAA, the United States' tidal shoreline is 95,471 miles long [5], of which 60,342 miles is along the lower 48 states. Estimates for the number of people that could be impacted by SLR vary, based on the expected depth associated with the SLR, but range from a potential 4.2 million people at immediate risk of inundation given $0.9 \mathrm{~m}$ SLR to 13.1 million people at immediate risk given a $1.8 \mathrm{~m}$ risk in the year 2100 [6]. Median estimates for the level of SLR range from 30 centimeters to 111 centimeters depending on the progress in mitigating greenhouse gas emissions $[7,8]$.

Because coastal areas have historically been attractive areas to establish communities, the predicted SLR leaves many systems along the coast vulnerable to damage. A total of 60,000 miles of US roads and bridges in the existing coastal floodplain are already at risk to extreme storms and hurricanes [2]. When put in perspective of the overall US economy, coastal zone counties account for $48 \%$ of GDP or $\$ 8$ trillion dollars [9].

The size and extent of this threat is focusing discussions on the question of what should be done to protect coastal communities from the threat of sea level rise as well as the increasing threat from coastal storm surge. This discussion crosses the political, economic, and engineering domains as the question emerges as to the appropriate approach that should be taken in response to the threats [10-13]. While the scientific determination 
of what areas are at the greatest risk continues to dominate the discussion, the challenge of how to respond to this vulnerability requires greater attention. Specifically, the question of whether SLR vulnerability requires new policies to relocate communities, or new investments to construct protection barriers, or whether communities should take a waitand-see approach is one that needs further attention.

Currently, the approaches to SLR response can be divided into three broad categories: protection, accommodation, and retreat. The protection category includes creating dikes, surge barriers, closure dams, constructing dunes, nourishment and sediment management of wetlands, creating coast defenses, sea walls and land claims, creating saltwater intrusion barriers and implementing drainage systems/polders. The accommodation category includes implementing building codes to minimize the flooding of critical building spaces, ensuring land use planning that accommodates for wetland loss, changing water extraction practices, using freshwater injections to stop saltwater intrusions and increasing the delineation of natural hazard areas. Finally, practices that pertain to retreating focus heavily on policies that minimize new building in areas where SLR threatens infrastructure, as well as considering the movement of existing structures in threatened areas [1].

While protection, accommodation, and retreat present a large array of approaches to protecting against SLR, historically, the implementation of sea walls, also known as rock revetments or armoring, has been the most common approach to reducing the impact of ocean activity on coastal communities [14-15]. Similarly, the building of inland sea walls, also known as bulkheads, along the banks of inland waterways have been a common approach to protecting property against rising waterway levels. While these are the predominant approaches to protecting coastal properties, seawalls do not work in every circumstance. Specifically, in cases where porous materials such as limestone form the bed of the waterway, water can infiltrate through the rock and under the seawall. In these cases, alternatives including the addition of pumping may be necessary.

Based on the historic focus on sea walls as a protection strategy, the current study provides a national estimate of the construction costs associated with armoring areas of the coast that are projected to be flooded and which contain built assets. These assets include both public and private assets such as roads, rails, and public buildings. Private residences are not specifically modelled in this effort but are included indirectly by protecting the locations that include roads and other public infrastructure elements that support these properties.

The intent of the current study is to provide the best estimate of expenses that have the highest likelihood of being incurred over the next 5-10 years. The study utilizes inundation projections from the lower bounds of those published to ensure that the overall results provide an indication of hard costs that are likely to be incurred by local, regional, and national entities.

The cost estimates presented here are considered conservative in that they are estimated construction costs that may increase due to specific conditions in local areas. The costs also do not include long-term maintenance costs or the potential for cost increases due to inflationary pressures. Thus, the actual costs incurred by municipalities is likely to be higher than the costs presented in this study.

\section{Literature Review}

The analysis of sea level rise impact is a growing field of study. A variety of approaches have been used to model the potential economic, social and environmental costs created by sea level rise. These procedures vary in methodology used, geography assessed, and scale implemented.

The first class of models consists of systems that are used to predict and model the amount of land along the coastline that will be inundated which may include; inundation models and Sea Level Affecting Marshes Model (SLAMM) [16]. Inundation models 
utilize climate models to predict what areas will be flooded, using Geographic Information Systems (GIS) and Digital Elevation Models (DEM). SLAMM specializes in incorporating habitat changes and processes that are likely to be impacted by climate change. Kirshen et al. take a more simplified approach to modeling the impacts of sea level rise by "developing damage-flooding depth probability exceedance curves for various scenarios over a given planning period and determining the areas under the curve" [17].

Neumann at el. incorporate "a tropical cyclone simulation model, a storm surge model and a model for economic impact and adaptation" to estimate the impacts of sea level rise for the US coastline through 2100. The model integrates site-specific elevation, land subsidence and property value data to estimate the costs incurred due to shoreline armoring, beach nourishment and property abandonment. Neumann et al. identify that coastal areas are densely populated, further intensifying the impact of sea level rise on human populations [18-20].

In addition to measuring the financial impact of land inundation, ecological landscape spatial simulation models account for the detrimental environmental consequences of SLR. The Ecological landscape spatial simulation models are a category of model that broadly analyze environmental factors such as subsidence, sea-level rise, changes in river discharge, and climate variability and their impacts on coastal habitats. These models are able to incorporate a larger range of variables including "coastal and estuarine hydrodynamics, water-borne particle transport, vegetation growth and infrastructure risk". However, due to this level of detail, these models can be expensive and time-consuming to run. The Dynamic Interactive Vulnerability Assessment (DIVA) model integrates biophysical and socioeconomic consequences of sea-level rise and is able to assess the costs and benefits of adaptation to the predicted impacts. DIVA is designed to incorporate a large variety of factors and components at a global scale and size. Similarly, SimCLIM models the biophysical and socioeconomic impacts of climate change and variability. The tool estimates how future climate and sea-level changes impact sectors and associates a sensitivity analysis with the modeling. The tool can be applied to local and global scales, depending on the availability of data.

The final category of model used to predict and understand the impacts of SLR account for the social impact on coastal communities and economies. Hsiang et al. utilize SEAGLAS (Spatial Empirical Adaptive Global-to-Local Assessment System) to estimate the cost of climate change to the sectors of agriculture, crime, coastal storms, energy, human mortality and labor using a "risk-based approach" which is "grounded in empirical longitudinal analyses of nonlinear, sector-specific impacts". The results suggest that climate change costs approximately $1.2 \%$ of the gross domestic product per $+1^{\circ} \mathrm{C}[21]$.

\section{Methods}

Building on existing methodologies as well as new approaches developed for the current study, the current study employs a multi-step process incorporating climate projections, geoprocessing of detailed coastline flooding maps, the computational assessment of where coastline needed protection, and the calculation of the costs associated with this protection. The process developed for this estimation is based on previous climate impact work developed by the authors for infrastructure impacts locally, regionally, and globally [22-24].

\subsection{Geoprocessing}

The first step in the impact process was the identification of areas where inundation and flooding were projected along the coastline and inland waterways. The study utilized SLR and 1-year storm surge inundation projections from Climate Central through highresolution data sets for the contingent United States coast based on published sea level rise projections as well as research conducted by Climate Central [25-27]. The data sets included analysis of the coastline at a 5-meter $x$ 5-meter grid to ensure accurate capture of 
tidal inlets. Each geographic location in the data set provided information on whether the location was projected to be inundated and if so, to what depth the inundation was expected.

As stated previously, the focus of the current study is to provide the best estimate of expenses that have the highest likelihood of being incurred in the next 5-10 years. From this perspective, the study includes the two lower projection RCP pathways, RCP 2.6 and RCP 4.5, to provide an estimate of expenses that have the highest likelihood of being incurred. The inundation data sets provided for the study were derived from a Monte Carlo simulation set of 10,000 projections generated by Climate Central. Specifically, the $5^{\text {th }}, 50^{\text {th }}$, and $95^{\text {th }}$ percentile inundation projections for each of the two pathways from the overall dataset were selected for the current study. Three time periods were selected from the results for the impact analysis; 2040, 2060, and 2100. Additionally, the inundation data was included with and without 1-year storm surge projections to capture both the base SLR impact and the potential for regular flood impacts. These combinations resulted in a total of 36 different scenarios for use in the study.

Similar to the projection data, Climate Central provided GIS files of infrastructure locations based on previous work and public database information [28] (Figure 1). This infrastructure included a broad range of public infrastructure including schools, hospitals, medical facilities, government buildings, airports and all public horizontal infrastructure (roads, railways and runways). Although the study does not consider private residences directly, the location of most residential areas can be determined through the location of public roads that are used to access residential areas. Therefore, by considering all areas that contain a road (both paved and unpaved), the majority of residential areas were also considered. Areas that do not have any public infrastructure, such as national parks or protected wildlife areas, were not included in the study.

A transformation of the data was performed to reduce the datasets to an indication of whether infrastructure was in a specific area and whether that area was projected to be impacted by SLR or storm surge. Although the original climate data was provided at an ultra-high resolution, for processing speed, usability and accuracy, the data was condensed to a uniform grid size. Sensitivity analysis tests were performed to determine an appropriate grid size that would allow for the most accuracy in results while still maintaining computability speed. The sensitivity analysis focused on determining the largest grid size that would both retain the underlying inundation detail as well as accurate location information for the infrastructure being analyzed. Through a series of test runs of increasing grid sizes, the sensitivity analysis found that a grid system of $150 \mathrm{~m}^{2}$ would achieve the research objectives (Figure 2). 


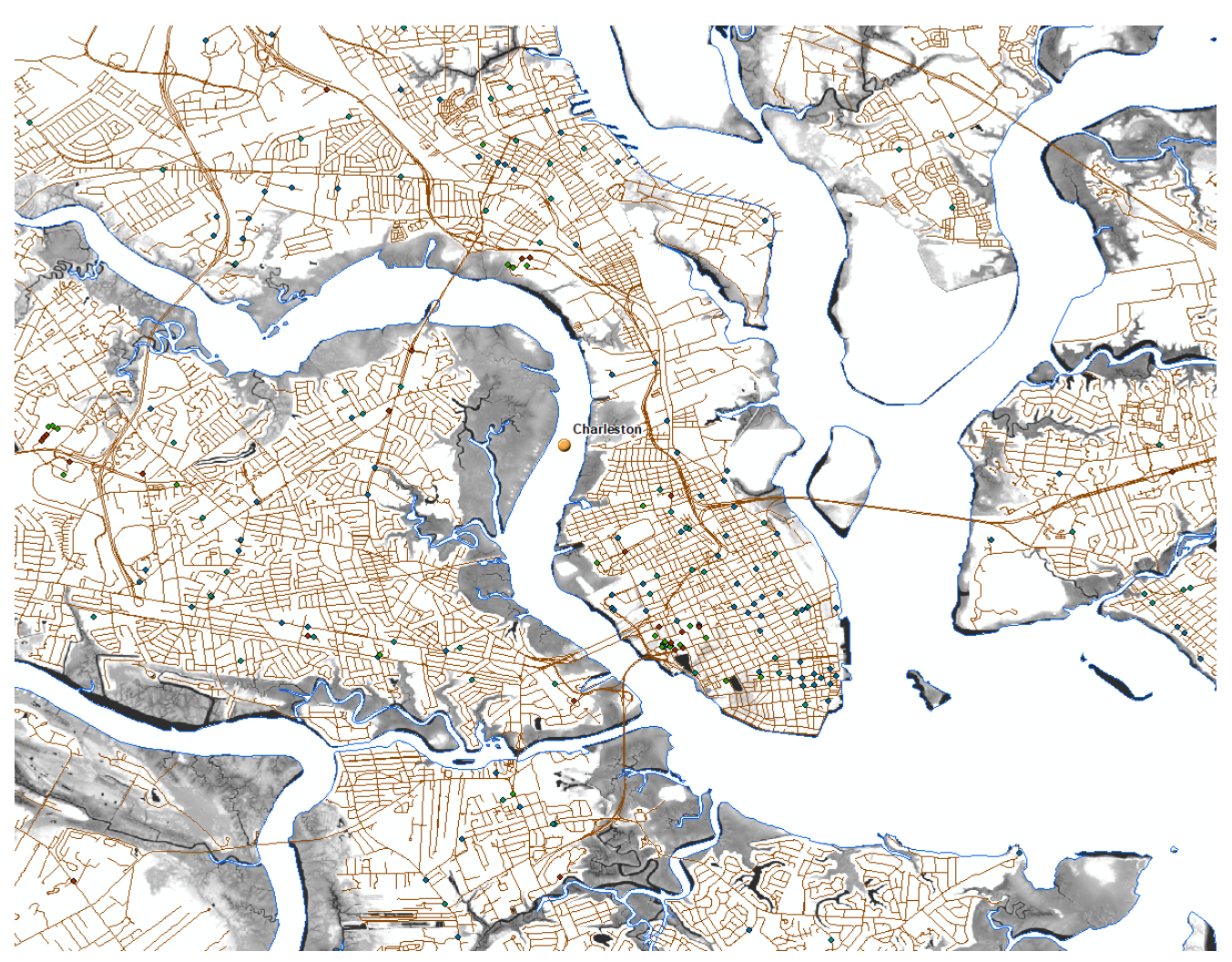

Figure 1: Flooding areas combined with infrastructure to be protected. Areas where infrastructure intersects with flooding are considered vulnerable and require protection. Shaded areas indicate flooding from this scenario. 


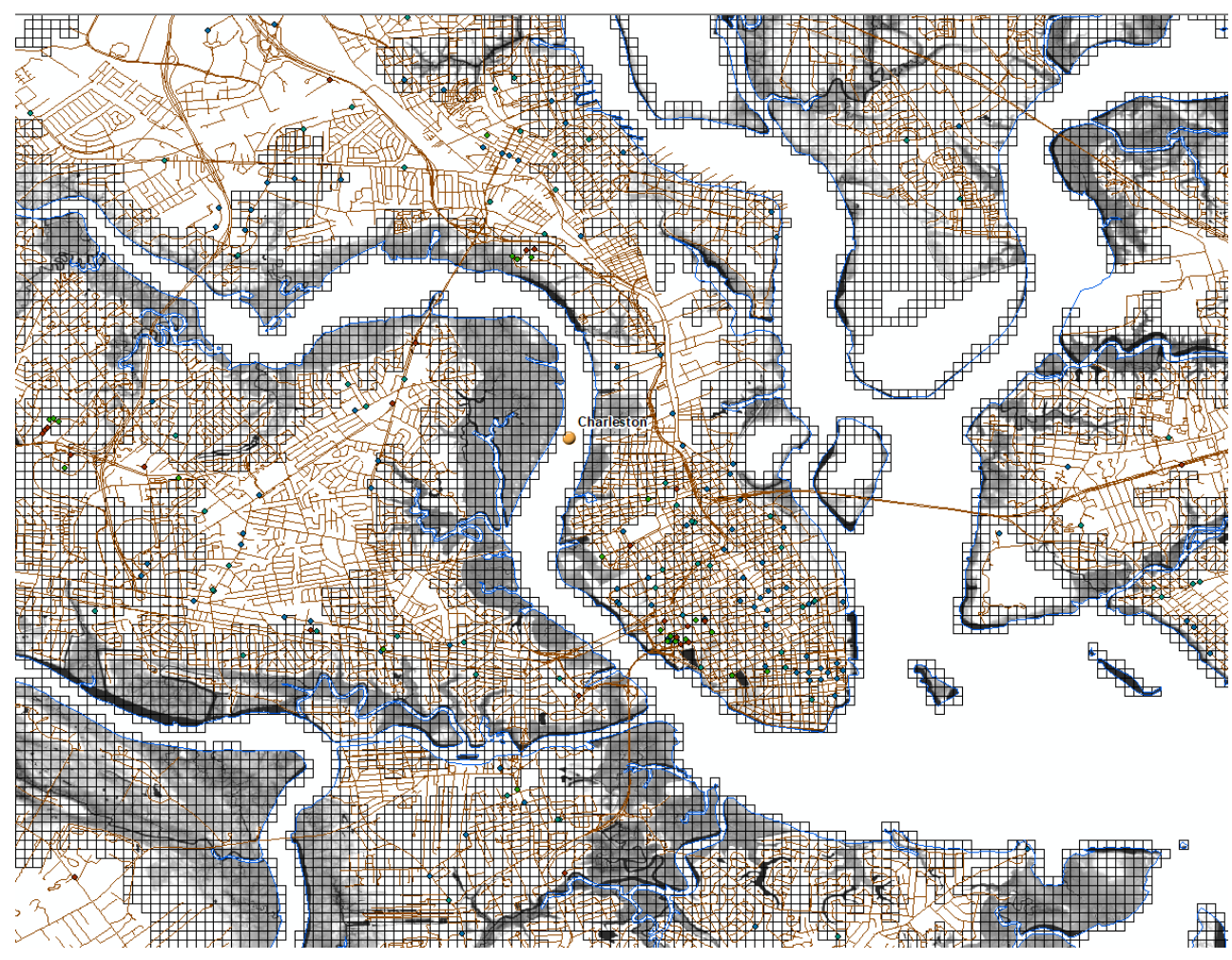

Figure 2: The $150^{2} \mathrm{~m}$ grid overlayed on the infrastructure and inundation zones. Each grid contains the information on the projected flooding and the infrastructure to determine length of protection required for each grid. 


\subsection{Protection Assessment}

Once the flooding files were processed, the second step of the process required determining what areas of coastline needed protection to remove the threat of flooding. This determination requires a series of logic tests to understand if a flooded grid is directly impacted by flooding from adjacent waterways, or if it is indirectly affected by other grids that are adjacent to waterways.

The first step in this process was to determine if any given gridded square is located within an area that is expected to flood, according to a specific climate scenario. This question is nuanced in that there must be a determination as to how much of a grid cell needs to be flooded for it to be considered a flooded grid. The need for this determination originates from the issue of how to limit the protection of coastal grids that appear in the study with minimal flooding along the edge of the coastline. For example, a grid covering an inlet which is indicated to have inundation over an area covering just a few yards onshore, and does not include flooding of any infrastructure, can be eliminated in terms of needing protection. The study adopted a threshold of $15 \%$ minimum inundation area to eliminate overprotection scenarios. The value of $15 \%$ was chosen based on engineering judgement upon inspection of protection patterns using $5 \%, 10 \%, 15 \%$ and $20 \%$.

The second issue focused on whether a grid was flooded due to direct flooding or indirect flooding. The model works from the assumption that wherever flooding occurs, the shoreline directly impacting that flooded area needs to be protected. The case of direct flooding occurs when a grid is adjacent to a waterway and the scenario indicates that grid is flooded due to an overtopping of the adjacent waterway. In this case, the adjacent shoreline needs to be protected to prevent the grids from incurring flooding. The indirect case occurs when an inland grid is flooded due to being connected directly or indirectly to a water-facing grid. In this case, the model must trace the path of the flood back to its origin which is the grid adjacent to the coastline. The model then protects the coastline adjacent to the grid to eliminate the threat to the overall flood area.

The identification of the flood areas provides the entry point for the final step in the process of calculating the length of coastline to be protected. The current study utilizes the NOAA Medium Resolution Shoreline Data in order to determine what is considered shoreline. This data set does not include HI, AK, PR, Guam, or other US territories. However, this data was selected to ensure that the results were consistent with the original data provided by Climate Central which was based on the NOAA Medium Resolution Shoreline Data. As illustrated in the map of Charleston, South Carolina in Figure 4, the NOAA map provides detailed imaging of the inlets and tidal areas within that geographic location. This is in contrast to lower resolution maps such as the coastline map from the Census Bureau which simplify the coastline as indicated by the red line that eliminates the inland portions of the coastline. The result of using this higher resolution map is that the actual length of coastline increases, in some cases significantly, as the true length of coastline can be calculated. In the current study this translates to a study length of approximately 135,000 miles in comparison to the NOAA measurement of approximately 95,000 miles.

After completing the protection length calculation, the model analyzed the coastline for every grid that was determined to have a flooding impact on identified infrastructure. For each of the identified grids, the length of coastline in that grid was calculated to a linear foot (Figure 3). 


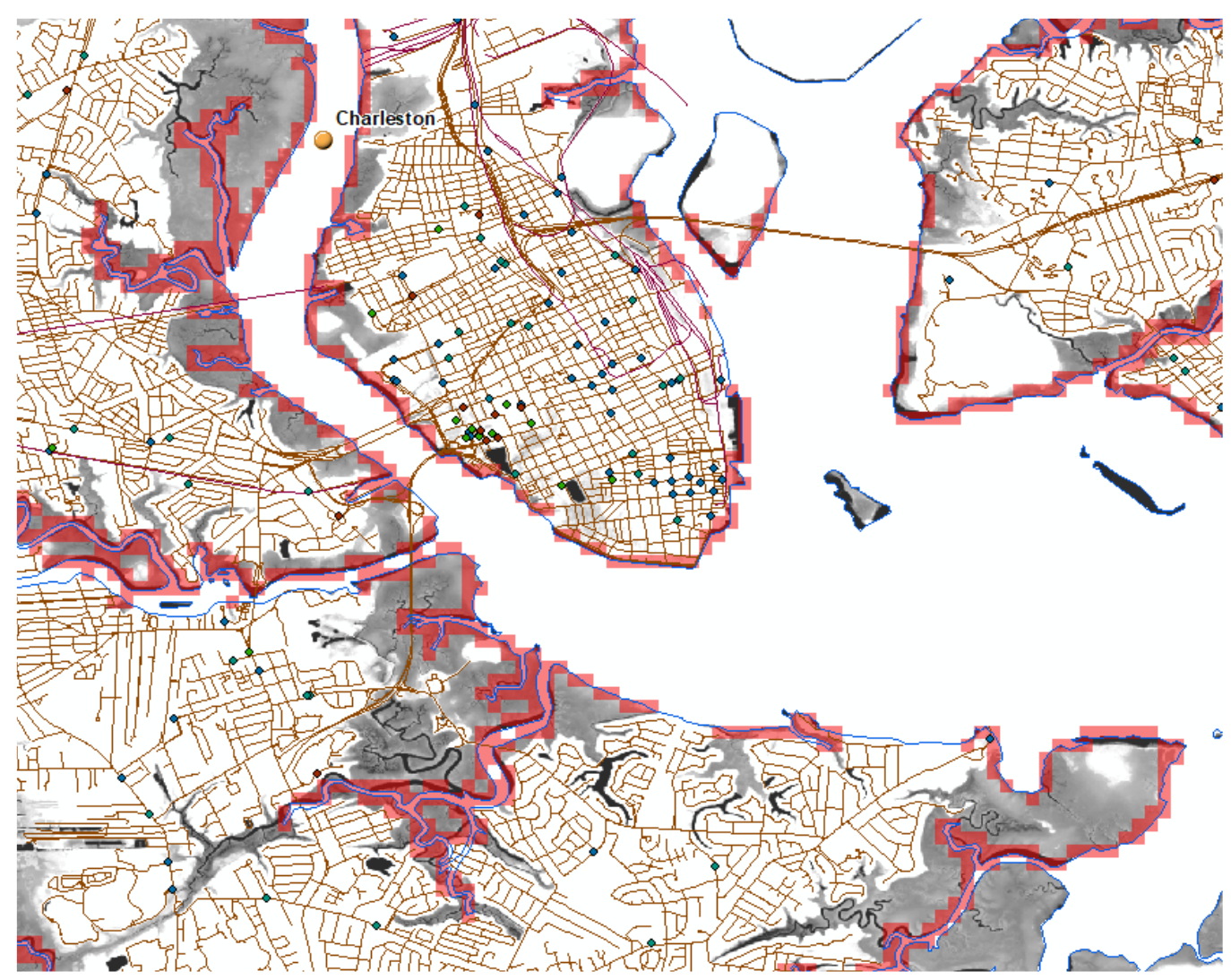

Figure 3: The $150^{2} \mathrm{~m}$ grid overlayed on the infrastructure and inundation zones combined with the projected protection zones. Each red grid indicates an area requiring protection. The blue lines indicate shoreline. 


\subsection{Costing}

Costing assessments for the study were created using a combination of national cost databases and local estimates from seawall design and construction companies to establish localized per-foot costs. The estimates were adjusted for location factor by state, based on the location of the sea wall.

The cost estimates are divided into two categories, coastal seawalls and inland seawalls. In terms of the former, coastal seawalls are comprised of armored revetments that are either adjacent to shore structures or serve as standalone offshore structures. The current study utilizes a typical design approach of using field stone to create an armored revetment on the shoreline. This design is utilized in the model wherever the coast exposure is direct to open water.

Inland seawalls, often referred to as bulkheads, focus on the protection of shoreline from an increased water level as well as from indirect wave action. Bulkheads are generally constructed of steel sheet piling, wood, or concrete where more permanent protection is required. The primary cost factor in these solutions is the installation which may vary depending on where the bulkhead is located.

\section{Results}

The protection of the coastline across 23 states is a significant task that will require the cooperation of national, regional, and local entities. As illustrated in Figure 8, a midlevel climate scenario in 2040 projects that every coastal-facing state is threatened by sea level rise and storm surge at a national cost conservatively placed at $\$ 416$ billion. This exposure elevates the SLR issue from a local problem that places the burden on local officials to a national issue that requires collaboration at all levels. In this section, the results of the SLR study are presented at the national, state, and county levels to emphasize the multi-jurisdictional impact of SLR.

As detailed in the methodology section, the current study analyzed 36 different climate scenarios to determine the potential impacts of SLR and storm surge. The $50^{\text {th }}$ percentile of the RCP4.5 scenario at 2040 is highlighted in the following sections. The results reflect the SLR and 1-year storm surge projections.

\subsection{National Results}

The construction cost to protect coastal infrastructure from SLR and storm surge is conservatively placed at $\$ 416$ billion in 2019 dollars when considering a projection using the $50^{\text {th }}$ percentile estimate of RCP 4.5. This estimate grows to $\$ 518$ billion in 2019 dollars when the same scenario is extended to 2100 (Figure 9). The number is slightly higher at $\$ 530$ billion when the $95^{\text {th }}$ percentile of RCP 4.5 is considered in 2100 . This number does not include maintenance costs, future replacement costs, or potential inflationary pressures due to a limitation of material or personnel resources.

Regionally, the western states (California, Oregon, and Washington) see a combined impact of $\$ 53.5$ billion by 2040 with California having the largest impact with a potential impact of $\$ 22.0$ billion. While this region is not discussed as often as Atlantic coast and Gulf coast states, the impact should not be minimized. California and Washington are ranked $6^{\text {th }}$ and $7^{\text {th }}$ respectively in terms of potential impacts from SLR and storm surge by 2040.

The Gulf coast states (Texas, Louisiana, Mississippi, Alabama, and Florida) see a combined impact of $\$ 142.9$ billion by 2040 with Florida having the largest impact with a potential cost of $\$ 75.9$ billion as the top ranked state for impact under this scenario. This region has received considerable focus for climate impact due to the potentially large impact on tourism and property values of coastal real estate (Fu et al 2016; McAlpine and 
Porter, 2018). However, this number grows significantly larger when the cost of protecting assets beyond real estate to include infrastructure as a general category is considered.

The southern half of the Atlantic states (Virginia, North Carolina, South Carolina, and Georgia) account for $\$ 101.2$ billion of costs by 2040. Notable among this group are North Carolina and Virginia which rank $2^{\text {nd }}$ and $3^{\text {rd }}$ in projected costs respectively. This region is already incurring damage-related costs in the billions of dollars due to increased nuisance flooding as well as from recent hurricanes. However, the projected impact from chronic SLR issues must not be overlooked. The long-term cost of chronic impacts will likely surpass those of one-time events.

Finally, the northern half of the Atlantic states (Maine, New Hampshire, New York, Massachusetts, Rhode Island, Connecticut, Delaware, Pennsylvania, New Jersey, Washington DC, and Maryland) account for the remaining \$118.7 billion. This region is notable for having states with considerable coastal infrastructure that requires protection such as in Maryland, Delaware, and New Jersey. In these locations, as in many of the high-cost states, infrastructure has been constructed over time in low-lying areas that extends to the coast with little or no buffer areas to protect property and infrastructure.

\subsection{State Results}

As illustrated in Table 1, Florida, Louisiana, and Virginia are the top 3 states in terms of projected protection costs. Each of these states have similar concerns in terms of SLR. Specifically, the extensive low-lying areas that exist together with the extensive infrastructure that has been built in the low-lying areas. While these vulnerabilities have been exposed in large events such as hurricanes, the potential risk from the topography is increased when the impact of SLR and storm surge is taken into account along the entire length of low-lying areas. 


\begin{tabular}{|c|c|c|}
\hline State & $\begin{array}{c}2040 \\
\text { (Billions USD) }\end{array}$ & $\begin{array}{c}2100 \\
\text { (Billions USD) }\end{array}$ \\
\hline Florida & 75.9 & 109.4 \\
\hline Louisiana & 38.4 & 42.3 \\
\hline North Carolina & 34.8 & 36.7 \\
\hline Virginia & 31.2 & 37.7 \\
\hline Maryland & 27.4 & 36.0 \\
\hline New Jersey & 25.0 & 29.3 \\
\hline Washington & 23.9 & 28.2 \\
\hline California & 22.0 & 27.3 \\
\hline South Carolina & 20.1 & 22.3 \\
\hline Texas & 19.3 & 26.6 \\
\hline Massachusetts & 18.7 & 24.0 \\
\hline New York & 17.4 & 24.0 \\
\hline Georgia & 15.1 & 15.8 \\
\hline Maine & 11.0 & 13.8 \\
\hline Delaware & 9.4 & 10.1 \\
\hline Oregon & 7.6 & 9.8 \\
\hline Alabama & 6.0 & 7.7 \\
\hline Connecticut & 5.3 & 6.7 \\
\hline Mississippi & 3.3 & 4.4 \\
\hline Rhode Island & 2.9 & 4.0 \\
\hline New Hampshire & 1.0 & 1.2 \\
\hline Pennsylvania & 0.5 & 1.0 \\
\hline Washington DC & 0.14 & 0.2 \\
\hline TOTAL & 416.3 & 518.5 \\
\hline
\end{tabular}

Table 1: Protection cost per state at 2040 and 2100 using the RCP 4.5 scenario at $50 \%$ to provide a mid-range estimate. 


\begin{tabular}{|c|c|c|c|c|}
\hline $\begin{array}{l}338 \\
339\end{array}$ & State & $\begin{array}{c}2040 \\
\text { (Miles) }\end{array}$ & $\begin{array}{c}2100 \\
\text { (Miles) }\end{array}$ & $\begin{array}{c}\text { Percent increase } \\
\text { from } 2040 \text { to } \\
2100\end{array}$ \\
\hline 340 & Alabama & 599 & 742 & $20 \%$ \\
\hline 341 & California & 1,785 & 2,244 & $20 \%$ \\
\hline 342 & Connecticut & 394 & 500 & $21 \%$ \\
\hline 343 & Washington DC & 21 & 30 & $30 \%$ \\
\hline & Delaware & 941 & 1,002 & $6 \%$ \\
\hline 344 & Florida & 9,243 & 12,765 & $28 \%$ \\
\hline 345 & Georgia & 2,460 & 2,522 & $2 \%$ \\
\hline 346 & Louisiana & 6,764 & 7,404 & $9 \%$ \\
\hline 347 & Massachusetts & 1,291 & 1,594 & $19 \%$ \\
\hline 348 & Maryland & 2,996 & 3,828 & $22 \%$ \\
\hline 348 & Maine & 1,267 & 1,566 & $19 \%$ \\
\hline 349 & Mississippi & 401 & 495 & $19 \%$ \\
\hline 350 & North Carolina & 5,250 & 5,404 & $3 \%$ \\
\hline 351 & New Hampshire & 122 & 142 & $14 \%$ \\
\hline 352 & New Jersey & 2,696 & 3,009 & $10 \%$ \\
\hline 353 & New York & 1,262 & 1,724 & $27 \%$ \\
\hline 353 & Oregon & 687 & 873 & $21 \%$ \\
\hline 354 & Pennsylvania & 66 & 130 & $49 \%$ \\
\hline 355 & Rhode Island & 247 & 344 & $28 \%$ \\
\hline 356 & South Carolina & 3,202 & 3,378 & $5 \%$ \\
\hline 357 & Texas & 2,739 & 3,632 & $25 \%$ \\
\hline 358 & Virginia & 4,063 & 4,928 & $18 \%$ \\
\hline 358 & Washington & 1,651 & 1,963 & $16 \%$ \\
\hline 359 & TOTAL & 50,147 & 60,219 & $15 \%$ \\
\hline
\end{tabular}

Table 2: Protection length in miles per state at 2040 and 2100 using the RCP 4.5 scenario at 50\% to provide a mid-range estimate.

Table 2 uses the same scenarios as that in Table 1, but places the information in terms of length of miles of seawall required to protect the infrastructure within the given state. As listed, it is projected that a minimum of 50,000 miles should be considered for protection by 2040 .

\subsection{City Results}

Cities are often the focus of SLR concerns and reports. Large cities including New York City, San Francisco, and Miami are often associated with the potential costs and risks of SLR. However, the risks of SLR go beyond these limited examples to cities of all sizes located in coastal zones. The current study addresses this oversight by specifically organizing the output in the context of the coastal cities of all sizes. The results are presented in multiple formats including total costs, per-capita and per-square mile contexts. These multiple perspectives were created by translating the underlying grids from the study to 
the geographic boundaries specified by the Census Bureau1. Table 3 presents the Top 20 cities at risk from SLR and storm surge based on the medium projection scenario.

\begin{tabular}{cccc}
\hline Rank & City & State & $\begin{array}{c}2040 \\
\text { (Millions USD) }\end{array}$ \\
\hline 1 & Jacksonville & FL & 3,461 \\
2 & New York & NY & 1,974 \\
3 & Virginia Beach & VA & 1,717 \\
4 & Marathon & FL & 1,507 \\
5 & Fire Island & NY & 1,450 \\
6 & Galveston & TX & 1,058 \\
7 & Charleston & SC & 1,032 \\
8 & Bolivar Peninsula & TX & 967 \\
9 & Tampa & FL & 938 \\
10 & Barnstable Town & MA & 889 \\
11 & Corpus Christi & TX & 861 \\
12 & North Key Largo & FL & 826 \\
13 & Poquoson & VA & 821 \\
14 & Islamorada, Village of & FL & 811 \\
15 & Islands & & 751 \\
16 & St. Petersburg & FL & 724 \\
17 & North Topsail Beach & NC & 718 \\
18 & Mobile & AL & 716 \\
19 & Seattle & WA & 708 \\
20 & Ocracoke & NC & 685 \\
& Dauphin Island & AL & 22,614 \\
\hline
\end{tabular}

Table 3: Protection cost for the Top 20 cities at 2040 using the RCP 4.5 scenario at $50 \%$. The city list does not include New Orleans, LA which would be number 16 at $\$ 725$ million due to the extensive protection already in place for New Orleans.

1 Data obtained from the US Census Bureau at https://www.census.gov/geographies/mapping-files/timeseries/geo/tiger-line-file.html 
A combination of inland waterway and coastal exposure creates one scenario where many of the top-listed cities such as Jacksonville, FL, are at risk. This scenario is similarly found in the other top cities including New York City, Virginia Beach, and Charleston. A second scenario exists in cities such as Marathon, FL, Fire Island, NY, and Galveston TX where the cities occupy an island location. In these scenarios, the protection requirements can extend throughout the island to protect infrastructure from SLR and storm surge.

\begin{tabular}{lcccr}
\hline $\begin{array}{c}394 \\
\text { Rank }\end{array}$ & City & State & $\begin{array}{c}\text { Population } \\
\text { (US Census Bureau) }\end{array}$ & $\begin{array}{r}\text { 2040 Per-Capita } \\
\text { (Millions USD) }\end{array}$ \\
\hline 3961 & Fire Island & NY & 246 & 5.89 \\
${ }_{397}$ & Dames Quarter & MD & 157 & 3.89 \\
3 & Frenchtown-Rumbly & MD & 133 & 2.65 \\
398 & Gilgo & NY & 146 & 1.99 \\
4 & Ocracoke & NC & 404 & 1.75 \\
3995 & Fairmount & MD & 306 & 1.46 \\
4006 & Napeague & NY & 129 & 1.28 \\
4017 & Bald Head Island & NC & 225 & 1.09 \\
402 & Fishers Island & NY & 230 & 0.97 \\
90310 & St. George Island & FL & 740 & 0.91 \\
40411 & Cameron Parish & LA & 222 & 0.87 \\
40512 & North Key Largo & FL & 1,009 & 0.82 \\
40613 & Topsail Beach & NC & 366 & 0.74 \\
14 & North Topsail Beach & NC & 1,061 & 0.68 \\
15 & Deal Island & MD & 465 & 0.66 \\
40816 & Asharoken & NY & 446 & 0.65 \\
40917 & Aripeka & FL & 111 & 0.62 \\
41018 & Taylors Island & MD & 201 & 0.61 \\
41119 & Gwynn & VA & 426 & 0.58 \\
4120 & Strathmere & NJ & 257 & 0.54 \\
\hline 4
\end{tabular}

Table 4: Cost per-capita at the city level in 2040 under the RCP 4.5 scenario at $50 \%$. Minimum 100 population.

The Top 20 cities not only represent a diversity of geography, but also represent a diversity in per-capita and per-square area. Table 4 presents the overall list of Top 20 cities from a per-capita perspective. Many of these locations are either small towns located on islands, or beach towns located on coastal or inland waterways. 


\begin{tabular}{ccccc}
\hline Rank & City & State & $\begin{array}{c}\text { Land Area } \\
\text { (Sq. Miles) }\end{array}$ & $\begin{array}{c}\text { 2040 Per-Sq.Mile } \\
\text { (Millions USD) }\end{array}$ \\
\hline 1 & Fire Island & NY & 9.2 & 158 \\
2 & Holden Beach & NC & 2.75 & 157 \\
3 & Holmes Beach & FL & 1.68 & 156 \\
4 & Wrightsville Beach & NC & 1.4 & 153 \\
5 & North Beach Haven & NJ & 1.82 & 148 \\
6 & St. George Island & FL & 4.75 & 142 \\
7 & Old Field & NY & 2.07 & 134 \\
8 & Nahant & MA & 1.05 & 128 \\
9 & Piney Point & MD & 1.53 & 127 \\
10 & Islamorada, Village of Islands & FL & 6.45 & 126 \\
11 & Big Coppitt Key & FL & 1.15 & 119 \\
12 & North Topsail Beach & NC & 6.21 & 117 \\
13 & Rehoboth Beach & DE & 1.18 & 112 \\
14 & Dauphin Island & AL & 6.26 & 110 \\
15 & Gwynn & VA & 2.34 & 106 \\
16 & Duck & NC & 2.42 & 106 \\
17 & Tavernier & FL & 2.51 & 106 \\
18 & Deal Island & MD & 3.03 & 102 \\
19 & Westbrook Center & CT & 1.69 & 102 \\
20 & Belford & NJ & 1.26 & 97 \\
\hline
\end{tabular}

Table 5: Cost per-square mile at the city level in 2040 under the RCP 4.5 scenario at 50\%. Minimum 1 square mile in land area. 
The projected costs per population highlight the challenge of small cities in terms of the cost of protection versus the size of the city. The same challenge exists in terms of the size of the town in comparison to the threats facing the location. Of particular concern, are the small islands and coastal areas that either line the coast or lie adjacent to the mainland in areas along the Atlantic coast in particular. These areas often have small populations, but are popular tourist destinations. Protecting these areas, in particular the islands, can translate to significant costs when put in the context of the size of the area.

Table 5 illustrates a number of these smaller geographic areas with a minimum 1 square mile of land area and their costs on a per-square mile basis. As listed, these small areas can exceed $\$ 100$ million per square mile of area to protect the location.

As a comparison for the small area challenge, cities with a large cost, but also a large area where this cost is distributed include; New York City at $\$ 6.57$ million per square mile, Miami at \$4.82 million per square mile, and San Francisco at \$5.47 million per square mile. These results highlight a challenge for policy makers as to where to prioritize limited protection funds. Should priority be given to popular tourist areas with small populations, but a large risk factor, or should priority be given to urban areas that provide a larger return-on-investment ratio in terms of protection costs to area and population.

\section{Discussion}

Seal Level Rise and storm surge present a new risk and projected reality for coastal communities. This study highlighted a middle-of-the-road projection in 2040 and 2100 to emphasize a likely scenario of costs that cities and counties will face over the next 5-10 years. Figure 4 illustrates the 2040 and 2100 costs for each state under the conservative RCP 4.5 scenario. As illustrated, the majority of states incur the primary protection costs by 2040 and only a few see significant increases in 2100 .

The following sections focus on three issues that emerge from the current study; the response timeline, the urban versus rural challenge, and the protection feasibility challenge.

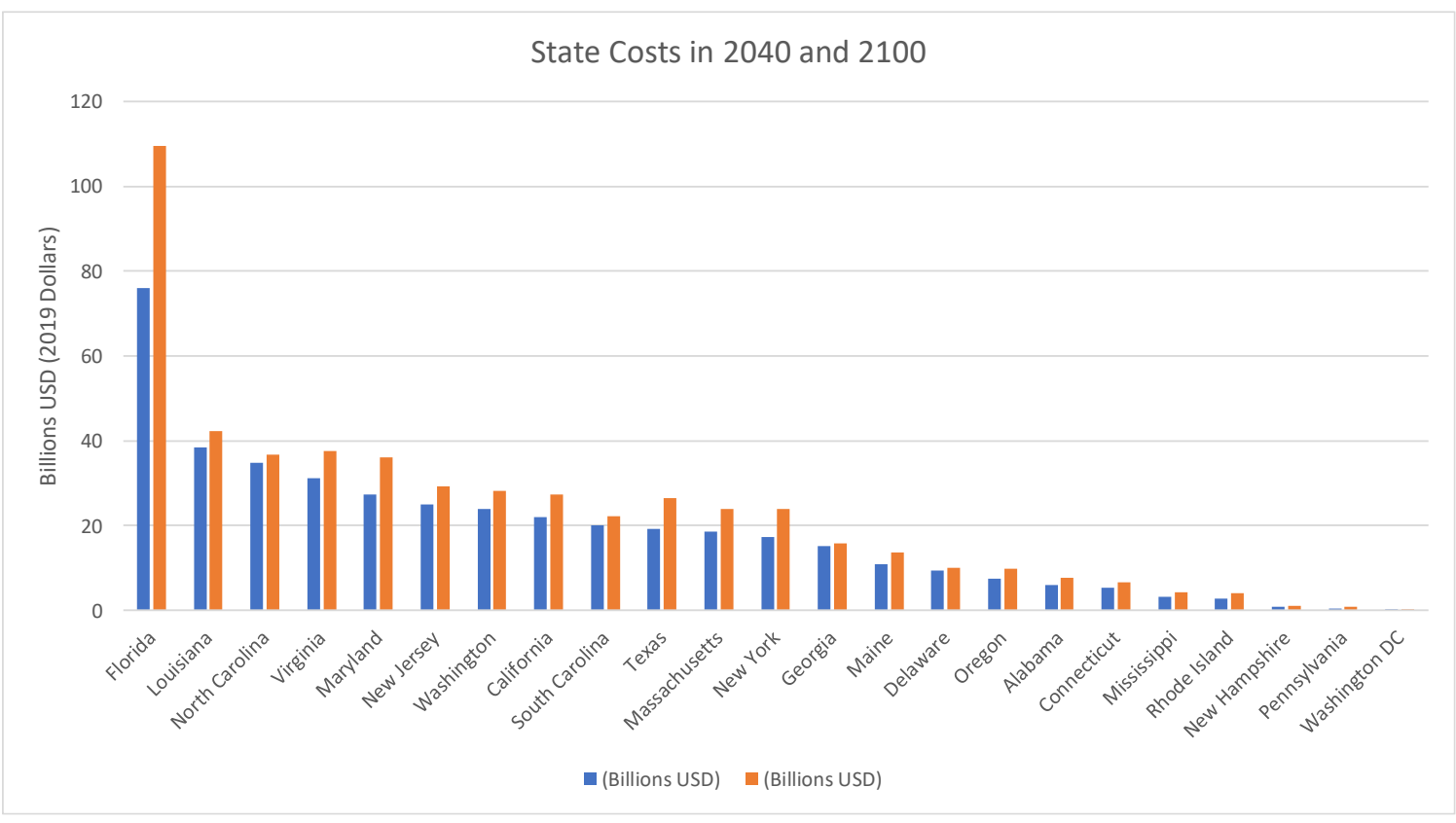

Figure 4: The range of projections for national costs from the RCP 2.6 and 4.5 scenarios at the 2040, 2060, and 2100 timeframes for low, medium, and high projections. 


\subsection{Response Timeline}

A key message from the data developed in this study is that the timeline for responding to the threat of sea level rise and storm surge begins now. The data for all scenarios included within this study indicate that SLR and storm surge will have a national impact by 2040 in the majority of locations. In addition to the projected cost factor, there is considerable effort required to plan and design for protective barriers. Issues such as environmental impacts, site-specific engineering solutions, and availability of expertise are issues that will extend the time required to implement protection solutions.

Given that additional cost and time will be required for almost all of the protection projects, consideration must be given to initiating discussions on this issue if they are not already started. The data in this study indicates that within 20 years, approximately $80 \%$ of the protection needed by 2100 to protect infrastructure from the SLR risk will already be required. In terms of the number of miles of protection required by 2040 , there is a projected need for over 50,000 miles of protection. This number only increases by $15 \%$ to just over 61,000 by 2100 . This increase reduces to $10 \%$ or less in states including Delaware, Louisiana, New Jersey, North Carolina, South Carolina, and Georgia.

The message from the data and the accompanying protection analysis is that the timeline for decision-making is sooner rather than later. The majority of impacts to infrastructure will occur by 2040 .

\subsection{Urban versus Rural}

The second challenge arising from the current study is the issue of where to prioritize protection from SLR and storm surge. As documented previously, depending on the perspective chosen, the cities at greatest risk will change in terms of cost. Table 6 provides a comparison of three cities with differing prioritization depending on the perspective. Holden Beach, NC is significantly higher in cost when viewed from a perspective of persquare mile costs. This measure indicates that the limited area of Holden Beach will require a significant investment to protect the infrastructure located in the town. In contrast, Jacksonville has a much smaller investment when viewed on a per-square mile basis. This would indicate that the relative cost of protecting the infrastructure in Jacksonville is less than that facing the community of Holden Beach. When viewed from a perspective of population, Dames Quarter, MD is a much more significant investment than the other two communities. Jacksonville appears to be a much smaller investment when placed in the context of a per-capita investment. Finally, from a total cost perspective, the perspective changes to show that Jacksonville will require a much greater investment than the other two communities. From this perspective, Holden Beach is the lowest cost investment at only $\$ 432$ million by 2040 .

\begin{tabular}{ccccccc}
\hline City & State & $\begin{array}{c}\text { Total Cost } \\
2040 \\
\text { (Millions } \\
\text { USD) }\end{array}$ & $\begin{array}{c}\text { Land } \\
\text { Area } \\
\text { (Sq. } \\
\text { Miles) }\end{array}$ & $\begin{array}{c}2040 \\
\text { Per-Sq.Mile } \\
\text { (Millions } \\
\text { USD) }\end{array}$ & Population & $\begin{array}{c}\text { Capita Per- } \\
\text { (Thousands } \\
\text { USD) }\end{array}$ \\
\hline Holden Beach & NC & 432 & 3 & 157 & 1,037 & 417 \\
Jacksonville & FL & 3,461 & 748 & 5 & 867,313 & 4 \\
Dames Quarter & MD & 611 & 12 & 52 & 157 & 3,890 \\
\hline
\end{tabular}

Table 6: Comparison of costs at a city level through the multiple perspectives of the current study. 


\subsection{Protection Feasibility}

The final issue that is highlighted here from the current study is the issue of the feasibility of implementing the required protection by 2040 . With 50,000 miles of sea wall to construct by 2040 , the issue arises as to the feasibility of constructing this volume of protection in time. The issue of feasibility incorporates multiple issues including; availability of design and construction personnel, availability of materials, and the potential from price increases due to micro-inflationary pressures.

In terms of personnel availability, the question focuses on whether there will be sufficient numbers of design and construction personnel available to design and construct over 2,000 miles of sea walls per year for the next 20 years. While there may be sufficient numbers of personnel in locations such as Florida and Louisiana where coastal engineering is a constant requirement, there may be issues in areas such as Washington where over 1,600 miles of sea walls is projected to be required.

Similar to the availability of personnel is the availability of construction materials. While coastal revetments primarily require rock and concrete which is more readily available, inland bulkhead seawalls require materials such as steel sheet piling. A large push to construct these bulkhead seawalls will put pressure on material suppliers in terms of how the prioritization will be made between seawall construction and the continuing requirements of materials for other projects. Delays in providing materials could stall the required protection projects for extended periods of time.

\section{Conclusion}

The current study is intended to open a new conversation on the impact of sea level rise and storm surge. It is not focused on the science behind the SLR risks, nor does it intend to add to the scientific question of whether there will be SLR or how much SLR there might be. Rather, the current study addresses the critical question of what is the potential impact of the projected SLR and storm surge. In the same manner as public officials plan for earthquakes, hurricanes, floods, and tornadoes, SLR is a natural hazard that deserves a complete range of discussions including how to minimize the damage if and when such an event occurs. At a conservative projection of a $\$ 400$ billion impact by 2040 , SLR can no longer be ignored or treated as a purely theoretical argument by public officials responsible for the health and safety of the general public.

In addition to encouraging public officials to include SLR in planning discussions, this study should encourage communities of all sizes to consider the monetary commitment required for protection against SLR. Whether the community is limited in physical area and population such as Dames Quarter, MD, or is one of the larger cities such as San Francisco, the impact of SLR will have significant financial impact.

The decision to address SLR is only the first step in addressing this complex issue. A single property owner, or even a single community, is not enough to address the overall threat from SLR. While a single owner may choose to retreat from the coastal area, or a community may elect to aggressively address SLR, this is an issue that requires cooperation and collaboration at the state, regional, and national levels. The successful implementation of a protection system requires neighboring communities and states to work together to ensure that engineered or natural systems work seamlessly along the coastline.

The issue of collaboration returns to the challenges addressed in the previous section. Prioritization must be considered when implementing any protection plan. The question of how to develop this prioritization is one with no easy solution. However, public officials have a choice; focus on the differences between the communities (size, population, total risk), or focus on possible solutions that can be mutually beneficial. The choice that is made will set the stage for the future of many communities. 
Funding: This research was funded by the Institute for Governance and Sustainable Development

\section{References}

1. Nicholls, R. (2011). “Planning for the Impacts of Sea Level Rise.” Oceanography, 24(2), 144-157.

2. US Department of Federal Highway Administration. (2008). Highways in the Coastal Environment. 250.

3. Jerry M. Melillo, Terese Richmond, and Gary W. Yohe. (2014). Climate change impacts in the United States: U.S. national climate assessment.

4. Jacobs, J. M., Culp, M., Cattaneo, L., Chinowsky, P. S., Choate, A., DesRoches, S., Douglass, S. L., and Miller, R. (2018). Chapter 12 : Transportation. Impacts, Risks, and Adaptation in the United States: The Fourth National Climate Assessment, Volume II. U.S. Global Change Research Program.

5. US Department of Commerce, N. O. and A. A. (n.d.). "How long is the U.S. shoreline?" $<$ https://oceanservice.noaa.gov/facts/shorelength.html> (Mar. 18, 2019).

6. Hauer, M. E., Evans, J. M., and Mishra, D. R. (2016). “Millions projected to be at risk from sea-level rise in the continental United States." Nature Climate Change, 6(7), 691-695.

7. Bamber, Jonathan L., Oppenheimer, Michael, Kopp, Robert E., Aspinall, Willy P., and Cooke, Roger M. (2-19). " Ice sheet contributions to future sea-level rise from structured expert judgment." Proceedings of the National Academy of Sciences May 2019, DOI:10.1073/pnas.1817205116

8. Schaeffer, M., Hare, W., Rahmstorf, S., and Vermeer, M. (2012). “Long-term sea-level rise implied by $1.5^{\circ} \mathrm{C}$ and $2{ }^{\circ} \mathrm{C}$ warming levels." Nature Climate Change, 2(12), 867-870.

9. Fleming, E., J. Payne, W. Sweet, M. Craghan, J. Haines, J.F. Hart, H. Stiller, and A. Sutton-Grier, 2018: Coastal Effects. In Impacts, Risks, and Adaptation in the United States: Fourth National Climate Assessment, Volume II [Reidmiller, D.R., C.W. Avery, D.R. Easterling, K.E. Kunkel, K.L.M. Lewis, T.K. Maycock, and B.C. Stewart (eds.)]. U.S. Global Change Research Program, Washington, DC, USA, pp. 322-352. doi: 10.7930/NCA4.2018.CH8

10. Neumann, B., Vafeidis, A. T., Zimmermann, J., and Nicholls, R. J. (2015). “Future Coastal Population Growth and Exposure to Sea-Level Rise and Coastal Flooding - A Global Assessment." PLOS ONE, (L. Kumar, ed.), 10(3), e0118571.

11. Butler, William H., Robert E. Deyle, and Cassidy Mutnansky. "Low-regrets incrementalism: Land use planning adaptation to accelerating sea level rise in Florida's Coastal Communities." Journal of Planning Education and Research 36, no. 3 (2016): $319-332$.

12. Yusuf, Juita-Elena (Wie), Katharine Neill, Burton St John, Ivan K Ash, and Kaitrin Mahar. "The Sea Is Rising... but Not onto the Policy Agenda: A Multiple Streams Approach to Understanding Sea Level Rise Policies." Environment and Planning C: Government and Policy 34, no. 2 (March 2016): 228-43. doi:10.1177/0263774X15614457.

13. Merrill, Samuel, Jack Kartez, Karen Langbehn, Frank Muller-Karger, and Catherine J. Reynolds. "Who should pay for climate adaptation? Public attitudes and the financing of flood protection in Florida." Environmental Values 27, no. 5 (2018): $535-557$.

14. Sutton-Grier, Ariana E., Kateryna Wowk, and Holly Bamford. "Future of our coasts: The potential for natural and hybrid infrastructure to enhance the resilience of our coastal communities, economies and ecosystems." Environmental Science E Policy 51 (2015): 137-148.

15. Griggs, G. B. (2005). “The Impacts of Coastal Armoring.” 73(1), 11.

16. Mcleod, E., Poulter, B., Hinkel, J., Reyes, E., and Salm, R. (2010). “Sea-level rise impact models and environmental conservation: A review of models and their applications." Ocean \& Coastal Management, 53(9), 507-517.

17. Kirshen, P., Merrill, S., Slovinsky, P., and Richardson, N. (2012). "Simplified method for scenario-based risk assessment adaptation planning in the coastal zone." Climatic Change, 113(3-4), 919-931.

18. Neumann, J. E., Emanuel, K., Ravela, S., Ludwig, L., Kirshen, P., Bosma, K., and Martinich, J. (2014). “Joint effects of storm surge and sea-level rise on US Coasts: new economic estimates of impacts, adaptation, and benefits of mitigation policy." Climatic Change, 129(1-2), 337-349.

19. Neumann, J., Hudgens, D., Herter, J., and Martinich, J. (2011). “The economics of adaptation along developed coastlines: Adaptation along developed coastlines." Wiley Interdisciplinary Reviews: Climate Change, 2(1), 89-98.

20. Neumann, J. E., Hudgens, D. E., Herter, J., and Martinich, J. (2010). “Assessing Sea-Level Rise Impacts: A GIS-Based Framework and Application to Coastal New Jersey." Coastal Management, 38(4), 433-455.

21. Hsiang, S., Kopp, R., Jina, A., Rising, J., Delgado, M., Mohan, S., Rasmussen, D. J., Muir-Wood, R., Wilson, P., Oppenheimer, M., Larsen, K., and Houser, T. (2017). "Estimating economic damage from climate change in the United States." Science, 356(6345), 1362-1369.

22. Cervigni, Raffaello, A. M. Losos, Paul Chinowsky, and J. L. Neumann. "Enhancing the Climate Resilience of Africa's Infrastructure: The Roads and Bridges Sector." Publication110137 (2016): 1-0.

23. Chinowsky, Paul, Jacob Helman, Sahil Gulati, James Neumann, and Jeremy Martinich. "Impacts of climate change on operation of the US rail network." Transport Policy (2017).

24. Schweikert, Amy, Xavier Espinet, and Paul Chinowsky. "The triple bottom line: bringing a sustainability framework to prioritize climate change investments for infrastructure planning." Sustainability Science 13, no. 2 (2018): 377-391. 
25. Kopp, Robert E., Robert M. DeConto, Daniel A. Bader, Carling C. Hay, Radley M. Horton, Scott Kulp, Michael Oppenheimer, David Pollard, and Benjamin H. Strauss. "Evolving understanding of Antarctic ice-sheet physics and ambiguity in probabilistic sea-level projections." Earth's Future 5, no. 12 (2017): 1217-1233.

26. Kulp, Scott, and Benjamin H. Strauss. "Global DEM errors underpredict coastal vulnerability to sea level rise and flooding." Frontiers in Earth Science 4 (2016): 36.

27. Tebaldi, Claudia, Benjamin H. Strauss, and Chris E. Zervas. "Modelling sea level rise impacts on storm surges along US coasts." Environmental Research Letters 7, no. 1 (2012): 014032.

28. Strauss, Benjamin H., Remik Ziemlinski, Jeremy L. Weiss, and Jonathan T. Overpeck. "Tidally adjusted estimates of topographic vulnerability to sea level rise and flooding for the contiguous United States." Environmental Research Letters 7, no. 1 (2012): 014033. 